\title{
Teaching and Reform of Analysis Chemistry To Freshman
}

\author{
Pan Bingli* \\ Public department of chemistry \\ Henan University of Science and Technology \\ Luoyang, China \\ e-mail:pblhaust@126.com \\ Wang Gengxian \\ Public department of chemistry \\ Henan University of Science and Technology \\ Luoyang, China \\ e-mail:wgx1961@163.com \\ * Corresponding Author
}

\author{
Liu Cuiyun \\ Department of chemical engineering \\ Henan University of Science and Technology \\ Luoyang, China \\ e-mail: liucy1218@126.com
}

\author{
Guo Jinwu \\ Public department of chemistry \\ Henan University of Science and Technology \\ Luoyang, China \\ e-mail: guojw@haust.edu.cn
}

\begin{abstract}
Analysis chemistry is a key basic course of freshmen in medical engineering and medical school. A part of students have difficult in learning it. Teachers should work hard to teach analysis chemistry because it is a very important curriculum with some characteristics. The author introduces a new teaching method of the application of case teaching method. Through the introduction of many practical teaching cases, the students' learning interest and enthusiasm are aroused. Main knowledge of analysis chemistry is given and teaching points are also maintained. In this way, the students deepen the understanding and mastery of knowledge of one of the branch of chemistry.
\end{abstract}

Keywords-teaching methods; freshmen; application; analysis chemistry; innovative ability

\section{INTRODUCTION}

Analytical chemistry is a fairly important basic course in medical or engineering college and universities, which is responsible for the basic knowledge of analysis science for the major of medical test, medicine examination, materials characterization, and so on.

Common analytical chemistry contains basic theories of chemical equilibrium and quantitative (and sometimes qualitative) analysis methods, especially for the part of basic theories of four chemical equilibriums with a fairly wide range of scientific knowledge. With the progress of educational reform of national college teaching, most of the colleges are compressing the class time of analytical chemistry course. The reduction of analytical chemistry course hours makes the situation worse. This must give considerable difficulty to the teacher's teaching and student's learning. What's more, China has implemented the new curriculum teaching system. During the execution of the new curriculum standards of basic chemical education, different cities and different regions have the time difference in the experimentation time. At the same time, the application of textbook materials is inconsistent. The factors above-mentioned make differences in the basic knowledge of what students studies. This would significantly influence the successive study in the university. In this context, it is necessary for the teacher to continuously innovate in the teaching way and art, inspire students' learning interest and passion to achieve good teaching results. The teaching class of analytical curriculum is very ideal place in the chemistry course to discuss topics such as chemical method select, experimental design, experimental result analysis and statistics, and the verification of the results. The topics are important in developing proper experimental protocols, and in obtaining experimental results. In recent years, the authors have carried out some exploration about case teaching method in the teaching practice of analytical chemistry, and have achieved good teaching results.

\section{INTRODUCTORY REMARKS OF CASE TEACHING METHOD}

The case teaching method was founded by Harvard University law school in 1920's of last century. The purpose of introduction of the method is to strengthen students' understanding of the legal rules and regulations. On account of good effect of this method, it has been applied to the teaching of sociology, management, economics, medicine and psychology.

The teaching process as-designed should be based on the active participation of students. The role of the teacher is not simply giving the lecture but performing the discussion of the specific events with the students in the class; the teacher should gradually summarize the key points of knowledge and solve the practical problem which the students face. The cases of questions, which mainly come from the fact during the practical work or life, are used to carry out teaching in the class. The questions should have the following five characteristics:

Knowledgeable;

Typical;

Pertinence and enlightening;

Interesting;

practical. 


\section{FIRST TYPICAL CASE}

One day in a hospital ward, after intravenous amoxicillin-clavulanic acid to one patient, ciprofloxacin lactate is dripping. When the two drugs are mixed in the infusion, a large number of micro yellow needle crystal precipitations appear. But ciprofloxacin that left in the transfusion bottle still keep clear.

It was found that the $\mathrm{pH}$ of amoxicillin-clavulanic acid was 8.76. While the $\mathrm{pH}$ was reduced to 6.59 , turbidity appears. When the $\mathrm{pH}$ was less than 4.13 , slight yellow needle crystal is precipitated. Therefore, the combination of amoxicillin-clavulanic acid injection with low $\mathrm{pH}$ ciprofloxacin ( $\mathrm{pH} 45 \sim 5.5)$ or gentamycin ( $\mathrm{pH}$ 4.0 6.0), precipitation will form. Adding $\mathrm{NaOH}$ solution to the system and increasing $\mathrm{pH}$ of solution, the solution becomes clear.

The students are divided in groups of five and begin to discuss. The designed questions are as follows:

What is the definition of acid and base?

How does the acid base property of the solution divide?

How to determine or calculate the $\mathrm{pH}$ of acid and base solution?

Let the students discuss these problems thoroughly; the teacher gives the following conclusions:

Many physiological and pathological phenomena of the human body are related to acid-base balance and sedimentation equilibrium. Acid-base balance of body fluid is one of the three basic balances of human body. Body fluids account for $70 \%$ of body weight, and they all have a certain degree of $\mathrm{pH}$.

The values of $\mathrm{pH}$ maintain stable in a relatively narrow range, and this acid-base balance is an important basis for the maintenance of human life activities. If this balance is destroyed, it will affect the normal activities of life. The acidosis or alkali poisoning will occur, which can lead to various diseases. Clinically, sodium lactate was used to correct the metabolic acidosis, and ammonium chloride was used in the treatment of alkali poisoning.

Preparation, analysis, and pharmacological effects of drugs are also often involved in acid base reactions and precipitation reactions. Many drugs themselves are acid or base. In order to ensure the safety and effectiveness of clinical medication, we should pay attention to the differences of $\mathrm{pH}$ among different drugs, and avoid the adverse effects caused by the change of $\mathrm{pH}$.

Acid-base property and acid-base balance is the basic theory of acid-base titration which is the first titration method with a very important role in common analytical chemistry. It is necessary that the relevant theory are fully understood to comprehend the acid-base titration process. Through the case discussion above-mentioned, the students will have a deeper impression of the acid-base balance theory, which is very important during studying analytical chemistry.

\section{SECOND TYPICAL CASE}

A typical case challenge classical analytical method. From the beginning of March 2008, an enterprise group began to receive some complaints that a famous infant milk powder can make infant suffer from urinary lithiasis. In early August, experts identified that the samples of the famous infant milk powder contain a large dose of melamine which can cause the problem of kidney disease, but they has not been announced.

In September, enterprise group declared to the consumer that they have commissioned a quality and technical supervision bureau to inspect the company's products. The results show that the tested infant milk powders conform to all of the national quality standards.

The most commonly used method for protein determination in milk is Kjeldahl, which is the most accurate and simple method for determination of total organic nitrogen among the determination of milk content. Therefore, Kjeldahl is as a statutory standard test method. The processes of method of determination of protein are as follows: sampling, sample digestion, distillation and titration steps.

The students are divided in groups of five and begin to discuss. The designed questions are as follows:

Which element does the method of Kjeldahl use to determine the content of the protein?

What is the defect of Kjeldahl method?

How to improve this method?

After the students have fully discussed the problems, the teacher concludes that the method of Kjeldahl is a way to determinate the content of element nitrogen in the substance. Protein is a kind of organic compounds containing nitrogen.

During the process of determination, protein in food is decomposed under the action of sulfuric acid and catalyst.

The produced ammonia can react and combine with sulfuric acid to produce ammonium sulphate. After the alkalization and distillation, ammonia is a free.

Free ammonia is reacted with boric acid to be absorbed, and it is titrated with sulfuric acid or hydrochloric acid standard solution. According to the amount of acid consumption multiplied by the conversion factor, you can calculate the content of protein in food. The determination method of nitrogen, Kjeldahl, cannot directly test the content of protein in food. It is necessary that the determination of other containing compounds in the food should be supplied to perfect the method and obtain the correct result of protein content.

It is one of the important goals of analytical chemistry education to cultivate students' ability to solve novel practical question or cultivate innovative ability. The example can be used to cultivate students' application ability of comprehensive chemistry knowledge.

Finding the deficiencies of theory of analytical methods is a relatively difficult task; once obtaining the ability, the advanced target is reached. The teachers can create the problem situation of some issues and give chance for students to integration of the science knowledge. By using this teaching art, the students can have a comprehensive impression of the typical analytical methods.

\section{THIRD TYPICAL CASE}

In April 2006, after using armillarisin injection of some pharmaceutical company, it leads to the result that a number of patients died of renal failure. Accident investigation results show that the problem occurred in the production by using diglycol as propylene glycol falsely. Propylene glycol is a kind of medicinal solvent, while the diglycol is the industrial solvent, and has a strong toxicity. 
How do you tell the difference between propylene glycol and diglycol? The Chinese Pharmacopoeia (2005 edition) has the provisions of the use of infrared spectroscopy to identify propylene glycol. In addition, there are a lot of substances which need to use infrared spectroscopy to identify in the Pharmacopoeia.

Before the class-teaching, the students prepare the relevant contents of the textbook and answer the following questions: what is the infrared spectrum? How is infrared spectrum produced? What is the role of infrared spectroscopy in the analysis of drug synthesis, extraction, separation and active components inspection? How to use infrared spectrum to perform qualitative, quantitative and structural analysis to substance? The answer is given in the form of homework.

During the class-teaching process, the teacher first focuses on the relevant knowledge of infrared absorption spectroscopy, and then combines the modern teaching method such as multimedia to display their detail structure information of the two compounds by infrared spectrum.

Through careful comparative analysis of the structure of the infrared spectrum, one can find that diglycol has a characteristic peak of $-\mathrm{O}$ - bond at $1150 \mathrm{~cm}^{-1}$ which is different from propylene glycol.

The students are divided in groups of five and begin to discuss. The designed questions are as follows:

why the molecule with two atoms have only one fundamental frequency peak, while those with many atoms have a number of fundamental frequency peaks?

Which factors are related to the number of fundamental frequency peaks?

What is the vibration form of the molecule?

Can the infrared spectrum be used for the identification of isomers?

Contrasting infrared spectrum between $n$-decane and ndecene;

Comparison of infrared spectra of toluene, o-xylene, $\mathrm{m}$ xylene and p-xylene;

Teachers give the content of classroom discussion timely comments and make some corrections at the same time.

While the students completed the analysis of actual case, the target of using the new chemical analysis theory to guide the practice is fulfilled. At last, the results of element analysis verified the composition and the structure of the compound were determined by infrared spectrum analysis.

In summary, the teaching process includes three contents in the case of the teaching practice:

a. the teacher lectured to the students on the basic theory systematically;

b. further explaining the key and difficult concepts through case analysis, or the introduction of the actual case with question;

c. from the actual case to the basic theory or from the basic theory to the actual case.

The first two steps can invert the order. On the one hand, the teacher can teach the basic theory, and analyze the actual case on the basis of the studied theory. On the other hand, according to the needs of the teaching, the teacher shows the practical case with question first, then teach the relevant concepts and explain the practical case with the concepts and theories. .

Let the students take the problem to learn the theory and the actual event. In this way of organic combination, it can accelerate and deepen the understanding of the theory of memory for the students. At the first stage, the range of case selection should include of the mature case of the industry. The teaching activity in the stage is dominated by teachers' explanation, and the students' discussion in group is as a complementary way. Step by step to cultivate students' ability to use analytical chemist' viewpoint and analyze in the face of scientific research and production.

In the second stage of case discussion, the students have basic analytical chemistry knowledge and skills. Many students have entered the research group. Some students have begun to pay attention to the development trends and hot issues of the related subjects. According to the scientific research project or the industry problem, the students begin to design the corresponding content of case. This contains that make-up title, design of the case content, case practice and case summary. In the process the students takes as the main body while the teacher takes as a guide.

The theory teaching and the practice case are organically mingled together, and the students can complete the study of basic theory of in the process.

Evaluation of teaching effect

We have an evaluation of the application effect of the case teaching method. We make use of the case teaching method and traditional teaching method of students at the same time for two parallel classes in past two years.

Evaluation index is the results of the final exam, which use the same paper and the same time to complete the answer. Full mark is 100 points, including the questions of filling in the blanks, choice questions, short answer questions and application of calculation.

We have applied two groups of students at the same time in two years of 2014 and 2015, and the corresponding results were recorded and statistical analysis was carried out. The results showed that the students who received the case teaching method have high scores than the traditional teaching method, and there are significant difference $(\mathrm{p}<0.01)$ in the two groups.

TABLE I THE DATA OF YEARS OF 2014

\begin{tabular}{|l|l|l|}
\hline \multirow{2}{*}{ Groups } & \multicolumn{2}{|c|}{ Major } \\
\cline { 2 - 3 } & pharmacy & medicine laboratory \\
\hline $\begin{array}{l}\text { Case teaching } \\
\text { methods }\end{array}$ & $80.15 \pm 8.89$ & $79.15 \pm 8.50$ \\
\hline $\begin{array}{l}\text { Traditional } \\
\text { teaching methods }\end{array}$ & $73.28 \pm 9.56$ & $71.85 \pm 9.25$ \\
\hline P-value & $\mathrm{p}<0.01$ & $\mathrm{p}<0.01$ \\
\hline
\end{tabular}

${ }^{*} \mathrm{p}<0.01$ means there are significant difference. 
TABLE II THE DATA OF YEARS OF 2015

\begin{tabular}{|l|l|l|}
\hline \multirow{2}{*}{ Groups } & \multicolumn{2}{|c|}{ Major } \\
\cline { 2 - 3 } & pharmacy & medicine laboratory \\
\hline $\begin{array}{l}\text { Case teaching } \\
\text { methods }\end{array}$ & $83.26 \pm 7.589$ & $81.15 \pm 7.05$ \\
\hline $\begin{array}{l}\text { Traditional } \\
\text { teaching methods }\end{array}$ & $75.15 \pm 9.56$ & $73.58 \pm 8.79$ \\
\hline P-value & $\mathrm{p}<0.01$ & $\mathrm{p}<0.01$ \\
\hline \multicolumn{2}{|c|}{$* \mathrm{p}<0.01$ means there are significant difference. }
\end{tabular}

\section{CONCLUSIONS}

The application of case teaching methods applied to a freshman college chemistry course teaching, achieved some success.

Analysis chemistry is as a key basic course of freshmen in medical engineering and medical school. A part of students have difficult in learning it. Teachers should work hard to teach analysis chemistry because it is a very important curriculum with some characteristics. The author introduces a new teaching methods of the application of case teaching method.

Through the introduction of many practical teaching cases, the students' learning interest and enthusiasm are aroused. Main knowledge of analysis chemistry is given and teaching points are also maintained. In this way, the students deepen the understanding and mastery of knowledge of one of the branch of chemistry. Our teaching and research office of the teaching method applied to teaching process of freshman's analysis chemistry course, and the results showed that the students who received the case teaching method have significantly high scores than the traditional teaching method.

\section{ACKNOWLEDGMENT}

The authors will be grateful to Mr. Zheng Xijun for his timely help. Financial support of this work was provided by the Fund of Henan University of Science and Technology (2008ZDYY004).

\section{REFERENCES}

[1] David Harvey, Modern Analytical Chemistry, 1st ed., Boston: McGraw-Hill, 2000.

[2] Chuan Qin,Guobin Rong. Strengthening case teaching in Organic Chemistry Teaching, Higher Education in Chemical Engineering, Aug. 2006, pp. 84-85.

[3] Lu Jiazheng, Jiang Jing Ceng Xiandong Liu Yunjun Guan Xiaoyan Yao Xiuqiong Chen Fei. Case teaching of inorganic chemistry in Medicine College, University Chemistry, vol. 26, Dec. 2011, pp. 16- 18 .

[4] L. Wan. Kjeldahl Determination of Protein in Food Discussion, Measurement and testing technology, vol. 39, Dec. 2012, pp. 89-90.

[5] J. Yang, Discussion on the technology and application of seawater desalination. Tianjin science and technology, Apr. 2007, pp. 79-81.

[6] X. Du, C. Wang. Discussion of Improving Learning Interest of Basic Chemistry. Guangzhou Chemical Industry, vol. 39, Dec. 2011, pp. 162-163.

[7] X. Xiao, L. Liao, Y. Lin, et al. Application of reverse case teaching method in anayltical chemistry teaching. Higher Education in Chemical Engineering, Aug. 2015, pp. 74-78.

[8] B. Pan, Educational Reform Of College Chemistry To Freshman. Guangzhou Chemical Industry, vol. 42, Aug. 2014, pp. 210-211.

[9] J. Yang, Q. Hu, F. Wei et al. study on application of case teaching method in anayltical chemistry teaching of pharmacy. Basic Medical Education, vol. 13, Aug. 2011, pp. 989-991.

[10] Q. Hu, Q. Huang, Analytical Chemistry (Edition of Case), 1st ed., Beijing: Science Press, 2000 